\title{
Can Oil Refiners Adjust to a Greater Supply of Shale Oil?
}

Walid Matar and Rami Shabaneh 


\section{Acknowledgements}

The authors thank Mark Finley and Alfredo Torres for their constructive comments that have improved the paper.

\section{About KAPSARC}

The King Abdullah Petroleum Studies and Research Center (KAPSARC) is a non-profit global institution dedicated to independent research into energy economics, policy, technology and the environment across all types of energy. KAPSARC's mandate is to advance the understanding of energy challenges and opportunities facing the world today and tomorrow, through unbiased, independent, and high-caliber research for the benefit of society. KAPSARC is located in Riyadh, Saudi Arabia.

This publication is also available in Arabic.

\section{Legal Notice}

(C) Copyright 2020 King Abdullah Petroleum Studies and Research Center ("KAPSARC"). This Document (and any information, data or materials contained therein) (the "Document") shall not be used without the proper attribution to KAPSARC. The Document shall not be reproduced, in whole or in part, without the written permission of KAPSARC. KAPSARC makes no warranty, representation or undertaking whether expressed or implied, nor does it assume any legal liability, whether direct or indirect, or responsibility for the accuracy, completeness, or usefulness of any information that is contained in the Document. Nothing in the Document constitutes or shall be implied to constitute advice, recommendation or option. The views and opinions expressed in this publication are those of the authors and do not necessarily reflect the official views or position of KAPSARC. 


\section{Key Points}

he production of light tight oil (LTO) in the U.S. has grown substantially in the last decade. Thus, a prevailing question in the oil refining industry is whether oil refiners can adjust to the increased supply of light crude oil. This study addresses this question using a long-term optimization model for the global oil refining industry. We operate the model over two-year recursive optimization horizons from 2017 until 2030, taking post-coronavirus crude oil supply projections from Rystad. The estimated API gravity of the projected LTO supply is 46. Products' demand projections are taken from the International Energy Agency but are adjusted for the recent demand reduction due to COVID-19. The main results are as follows.

Oil refineries respond to Rystad's projected future LTO supply growth by investing primarily in atmospheric distillation and hydrocracking capacity. LTO displaces more expensive lighter crude grades and is mixed with inexpensive heavier grades.

Without capital constraints, a 10\% rise in the LTO supply over the Rystad projections will decrease crude oil refining intake between 2020 and 2030. This finding suggests that the LTO product yields are better matched with the products being demanded. Thus, investment in atmospheric distillation should be reduced.

With capital constraints, an increase in the LTO supply causes total global refining costs to grow even more than in the reference case. This growth occurs because more expensive crude oil grades are blended with the additional LTO. 


\section{Summary}

$\mathrm{T}$ The advent of American shale oil and its prospects for continued production growth have raised concerns about whether oil refineries can handle the increasingly lighter crude oil supply. To provide a perspective on this issue, we run a global oil refining model for the years from 2017 to 2030 . The model's objective is to maximize refining industry profits in eight global regions, taking into account around 100 grades of crude oil. The model takes the prices of the crude grades as exogenous. However, the prices of the oil products are defined as the regional marginal costs of production determined by the model. The supply and demand series are adjusted to account for the post-coronavirus downturn.

We examine four scenarios. Our reference case takes the supply and demand projections as given. In an alternative case, we consider a $10 \%$ rise in light tight oil (LTO) output from the United States (U.S.) In the other two alternative cases, we place varying levels of capital constraints on refinery investments and assume that the LTO output increases.
In the reference case, oil refineries have no issues handling the additional supply of U.S. light crude oil. In some regions, oil refineries respond to the additional supply by investing in atmospheric distillation and hydrocracking capacity to increase their LTO intake. LTO displaces more expensive lighter crude grades and is mixed with inexpensive heavier grades. In the case in which the LTO supply is $10 \%$ greater than the Rystad projections, the crude oil refining intake between 2020 and 2030 is lower. This response suggests that the LTO product yields are better matched with the demanded products. Thus, investment in atmospheric distillation should be lower. When oil refineries have limited access to capital, however, a higher LTO supply leads to even higher total global refining costs than in the reference case. This result occurs because more expensive crude oil grades are blended with the additional supply of LTO. 


\section{Introduction}

he growth in light tight oil (LTO) production from shale formations in the United States

(U.S.) has been one of the most important energy industry events over the last decade. Between 2009 and 2019, U.S. crude oil production grew from 5.4 million barrels per day (MMb/d) to about $12.1 \mathrm{MMb} / \mathrm{d}$. LTO alone comprised about two-thirds of the U.S. production volume in 2019. During the same time period, U.S. net imports of crude oil decreased from 9.1 MMb/d to 3.8 MMb/d. Imports were displaced, and exports significantly increased. However, the growth in the volume of LTO was not the only noteworthy effect of this change in U.S. production. The quality of the crude oil from shale formations has added another dimension to the narrative that may prove challenging for both producers and refineries.

Analysts and market participants have differing opinions on the effects of the looming rise of LTO in the U.S. In particular, they disagree regarding the issue of crude oil quality. Experts' speculation in this regard stems from two main lines of discussion. The first addresses the mismatch between the anticipated growth in the demand for middle distillate and LTO's yield of naphtha-weighted products. The second argument is related to the existing refinery fleet, which, for decades, has largely been configured to process medium and heavy gravity grades. Cost-effectively handling lighter feeds is therefore challenging. U.S. refineries have already reached their limits in processing domestic LTO. Thus, some analysts believe that "we are going to hit a worldwide refining wall, with plants not suited to running such a light slate" (Alhajji 2018). Some integrated oil companies argue that refineries geared to process heavier crudes will take in light crudes not as baseload throughputs but rather as marginal volumes for top-ups (Sheppard 2018). The International Energy Agency (IEA), in contrast, has argued otherwise. It believes that the investments in refinery upgrades over the last two decades will be seen as sunk costs and not be considered when optimizing for daily crude intakes (Petrosyan 2018). This perspective has been supported by other analysts who believe that refineries will continue processing LTO if the price is right. Additionally, tighter policies on air pollutants, such as the International Maritime Organization's ruling limiting sulfur emissions from ships, favor low-sulfur oil, which LTO inherently is.

Thus, this study aims to examine the potential consequences of the increased U.S. shale oil supply on the global oil refining industry. To do so, we develop and calibrate an oil refining model to represent global operations. The model maximizes the global oil refining industry's total profit, and product prices are endogenously determined. The results should simulate the refining system's ability to adapt to a greater U.S. LTO supply and the levels of necessary investments under different assumptions.

To this end, we examine four scenarios. The first is a reference case scenario based on Rystad's oil supply projections as of spring 2020. This scenario is the base case against which three alternative cases are compared. These alternative cases include a scenario with more U.S. shale oil and two scenarios with more U.S. shale oil and varying levels of capital constraints. These alternative scenarios explore whether oil refining decisions change if the LTO supply is greater or capital expenditures are lower. Without capital constraints, the model allows refineries to make unlimited investments. Thus, the capital constraints allow for more realistic scenarios.

Importantly, the drop in oil prices due to measures countering the spread of the COVID-19 pandemic has slowed global upstream investments tremendously. The IEA (2020) estimates that 
upstream investments in the oil and gas sector will drop by $32 \%$ in 2020 relative to 2019 . This slowdown has immediately impacted U.S. LTO producers; given the short-term nature of shale oil production, they have significantly scaled back their volumes. However, according to Rystad Energy, U.S. oil production is expected to rebound in 2022 or 2023 and continue along its growth trajectory until the end of the decade.
The remainder of this paper is structured as follows. The next section provides an in-depth review of U.S. shale oil and crude oil quality. Then, we review the existing tools in the literature for analyzing long-term oil refining operations. We next describe the mathematical framework used for this study in the context of these existing tools and describe the scenarios considered in this study. Finally, we discuss the results and offer concluding remarks. 


\section{U.S. LTO Production and the Evolution of Crude Oil Quality Patterns}

Whe quality of crude oil is primarily a function of its density and sulfur content.

These characteristics indicate the level of processing required by refineries to optimally produce desired products. They also determine crude oil's value, which, in turn, can affect refinery economics. Oil's density is typically measured using an index developed by the American Petroleum Institute (API) called API gravity, which reflects crude oil's density relative to water. A higher API gravity value indicates a lighter crude oil (lower density). The classification of crude oil by its API gravity differs by region. In general, light and sweet crudes have API gravities of more than 35 degrees and have sulfur contents of less than $0.5 \%$ (Eni 2020). Medium grades generally have API gravities between 26 and 35 degrees, and heavy crudes have API gravities below 26 degrees. As the name suggests, LTO is characterized as a light crude. However, it falls on the high end of the light crude spectrum. Its API gravity is typically higher than 40 degrees and, in some cases, is even higher than 50 degrees with condensate properties. Thus, the increase in U.S. LTO production has triggered a change in the overall quality of U.S. crude oil over time. Specifically, the share of extra light grades of crude oil has increased. Figure 1 shows that the volume of extra light oil, oil with an API gravity above 40 , increased by over $45 \%$, or over 2 $\mathrm{MMb} / \mathrm{d}$, between 2015 and 2019. This time period corresponds with an increase in the share of LTO.

Figure 1. U.S. crude oil production by API gravity from January 1, 2015 to December 31, 2019.

14

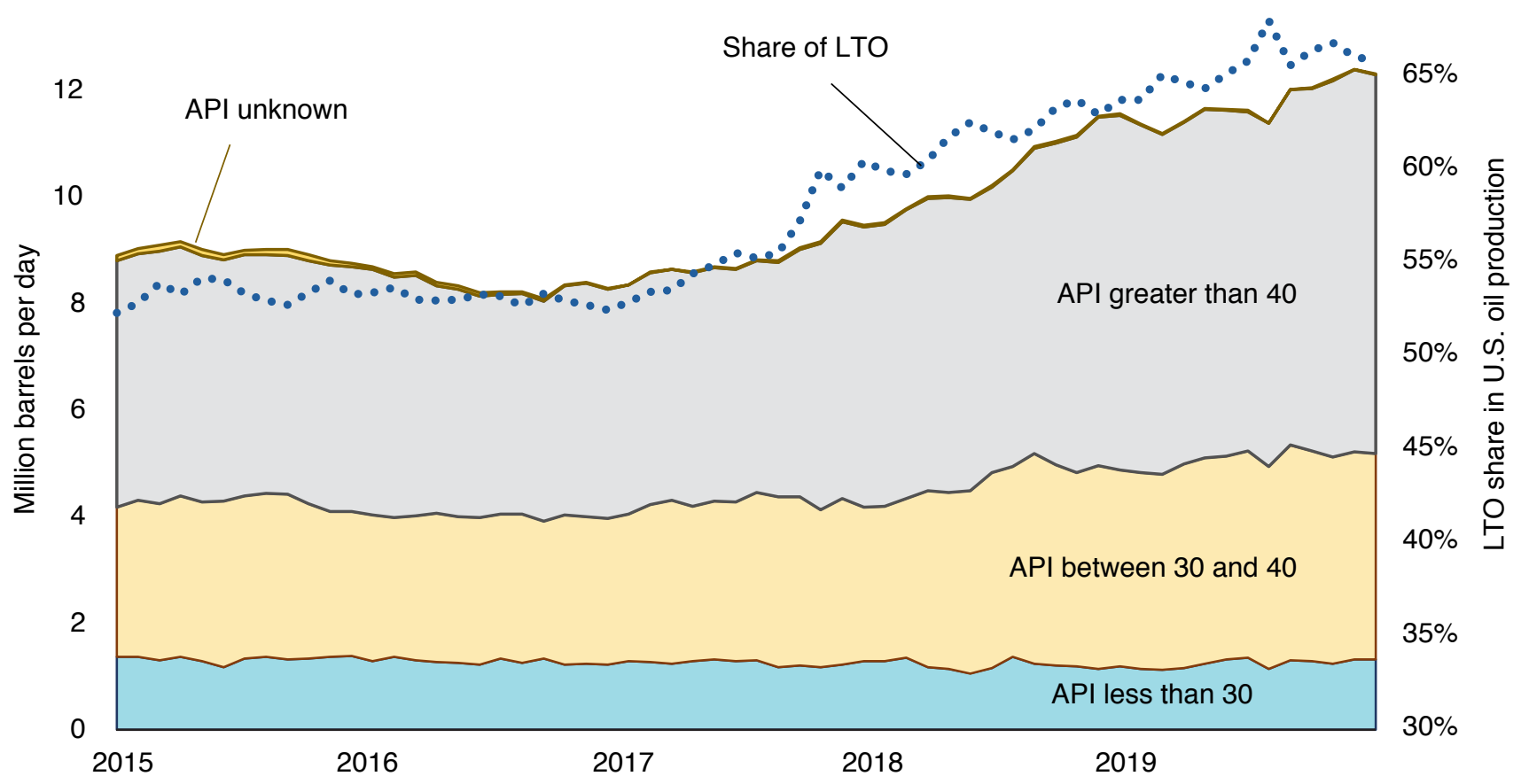

Source: U.S. Energy Information Administration (EIA). 
Figure 2 shows the assays of crude oils with varying API gravities, which reflect the yield patterns of the different refined products. In general, heavier crudes with lower API gravities yield much heavier hydrocarbon components, such as vacuum residue and vacuum gas oil, when passed through a refinery. These components need to be broken down further to be converted into desirable products. In contrast, lighter crudes produce larger shares of lighter cuts, such as distillates and naphthas. Refiners value light oils more highly than heavier crude oils because light oils require minimal processing to produce premium products. However, U.S. LTO is far lighter than typical light oils, skewing its product portfolio more toward naphthas. Thus, it can present challenges for refineries that are designed to process intermediate to heavier crudes.

In anticipation of heavier oils dominating supply, large investments were made to upgrade refineries in the U.S. throughout the 1990s and 2000s. In particular, deep conversion units were installed to turn oil residuum into gasoline and diesel (Kemp 2014). Thus, running LTO is sub-optimal, as it reduces the utilization of these new units, impacting refinery economics. Some refineries may also face physical constraints in processing LTO, as they have limited capacity to handle light ends.

Figure 2. Crude assays of different types with varying API gravities (by mass).

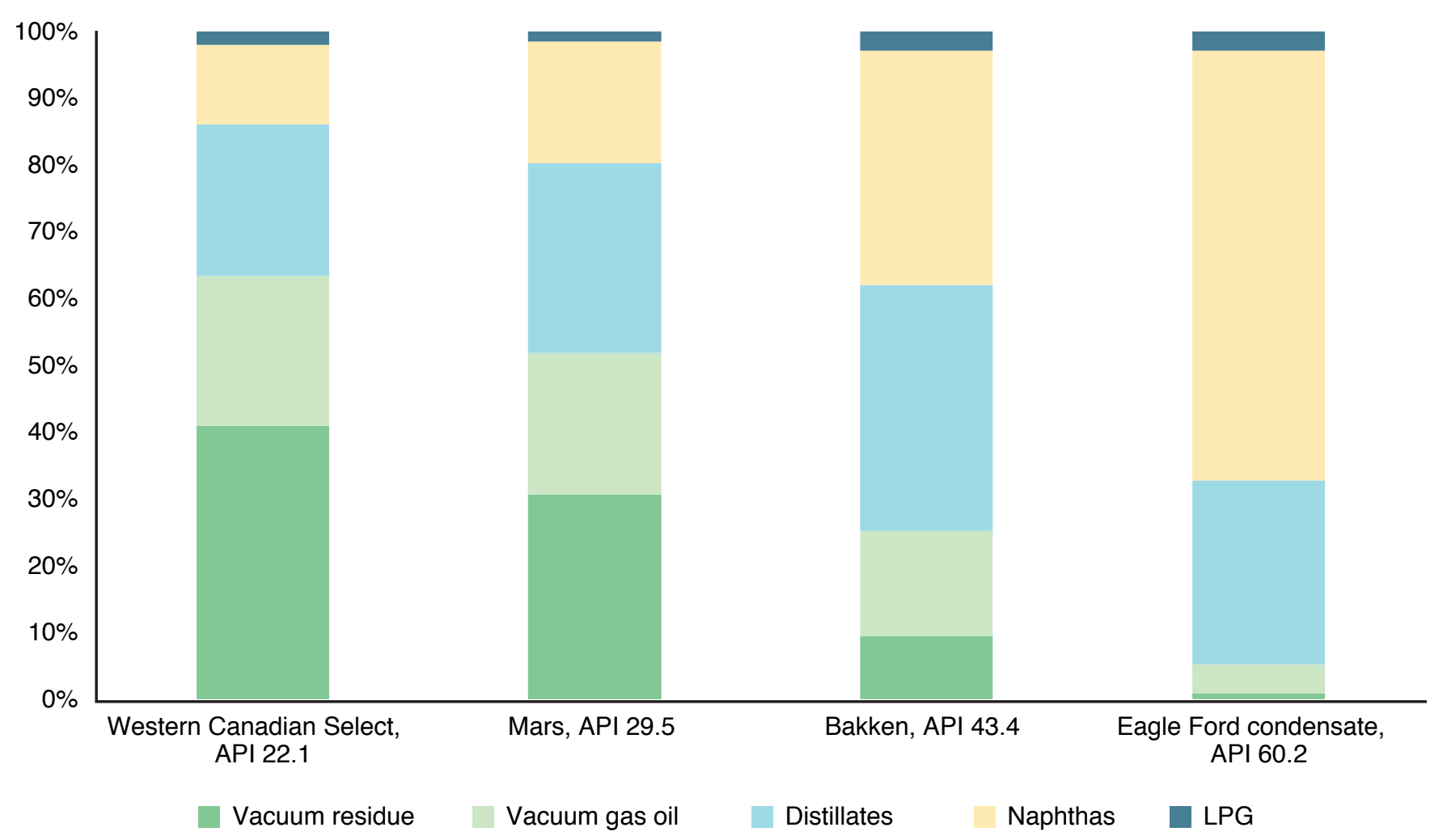


Following the surge in U.S. LTO production and before the export ban on crude oil was lifted in late 2015, the North American oil price benchmark, West Texas Intermediate (WTI), was heavily discounted relative to Brent crude oil. Some U.S. refineries chose to run more domestic LTO and reduce imports of light oils from global markets. Imports of medium grade crudes were also partially displaced by a 'look-alike' intermediate blend that refineries created by mixing LTO with heavy crude oil (EIA 2015). Price discounts on LTO and imported heavy crudes encouraged some refineries to continue this practice. However, blending limitations required investments to reduce bottlenecks at existing refineries and build additional capacity via topping units or condensate splitters.

The repeal of the export ban in 2015 acted as a relief valve for U.S. oil operators and allowed surplus U.S. LTO to be exported. The narrowing of the WTI-Brent price differential also allowed U.S. refineries to return to running the crudes for which they were optimally designed. However, the impacts of surplus volumes of LTO on future global refinery investments remain to be seen. Thus, in the following sections, we quantify the investments required by oil refineries to meet the projected demand for oil products under different LTO supply growth scenarios. 


\section{Review of Global Long-Term Oil Refining Models}

$M$ ost prior studies on oil refining models focus on short-term analyses and consider small spatial domains. These models typically have physical constraints and an in-depth characterization of processes (Castillo Castillo, Castro, and Mahalec 2017; Karuppiah, Furman, and Grossmann 2008). Oil refining models for long-term multi-regional planning are mainly incorporated in multi-sector energy system models and are linear in nature. They apply some physical parameters, such as processing unit yields for each input; crude oil parameters, such as mass density; and physical property specifications for products.

One such model is part of the National Energy Modeling System (NEMS), developed by the U.S. Energy Information Administration (EIA 2018). The NEMS includes an oil refining model that partially minimizes negative profits for U.S. refineries. This model incorporates profits from exported quantities while keeping product demand within the U.S. fixed.
We presume that the model maintains linearity, with marginal costs equaling prices, because it is solved iteratively. Rather than setting the price equal to the marginal cost variable in the objective function, it first solves but then sets the price parameter equal to the marginal cost from the previous run.

Additionally, Lantz et al. (2012) developed an oil refining model to be used alongside the Prospective Outlook on Long-term Energy Systems, a global energy model used for the European Commission. This model is based on mass balances between refining units. It minimizes refineries' costs, but it does take marginal cost pricing into consideration. Finally, another oil refining model used for long-term global analyses is the IEA's World Energy Model (WEM) (IEA 2018a). The WEM formulates oil refining by focusing on individual countries rather than aggregate regions. Unlike the previous two models, however, it does not aim to optimize costs or profits, and its refining structure is more simplified. 


\section{Method}

W

e develop and calibrate an oil refining model to represent global refining operations. This model is a modified version of the oil refining component of the KAPSARC Energy Model. The mathematical model is used only to support the claims made in this paper. It is meant to determine whether the refining industry can adapt to a higher shale oil supply through investment and illustrate the resulting profitability.

The model is constructed to maximize total industry profits, taking product demand as exogenous.

Product prices are endogenous, and the model represents a perfectly competitive market. We use the system of linear equations and inequalities described by KAPSARC (2016), but we add or amend some features of that system for this analysis. The model includes around 100 of the most commonly used crude oil grades and gas condensates. Crude oil is distilled, and gas condensate is split. The model divides the world into eight operating regions consisting of the 30 highest-producing countries, as defined in the appendix. Other countries are lumped into a generic category for each region. The model incorporates the refining capacities and demand for oil products in each region.

Figure 3. Oil refinery schematic employed in the model, calibrated to regional capacities.

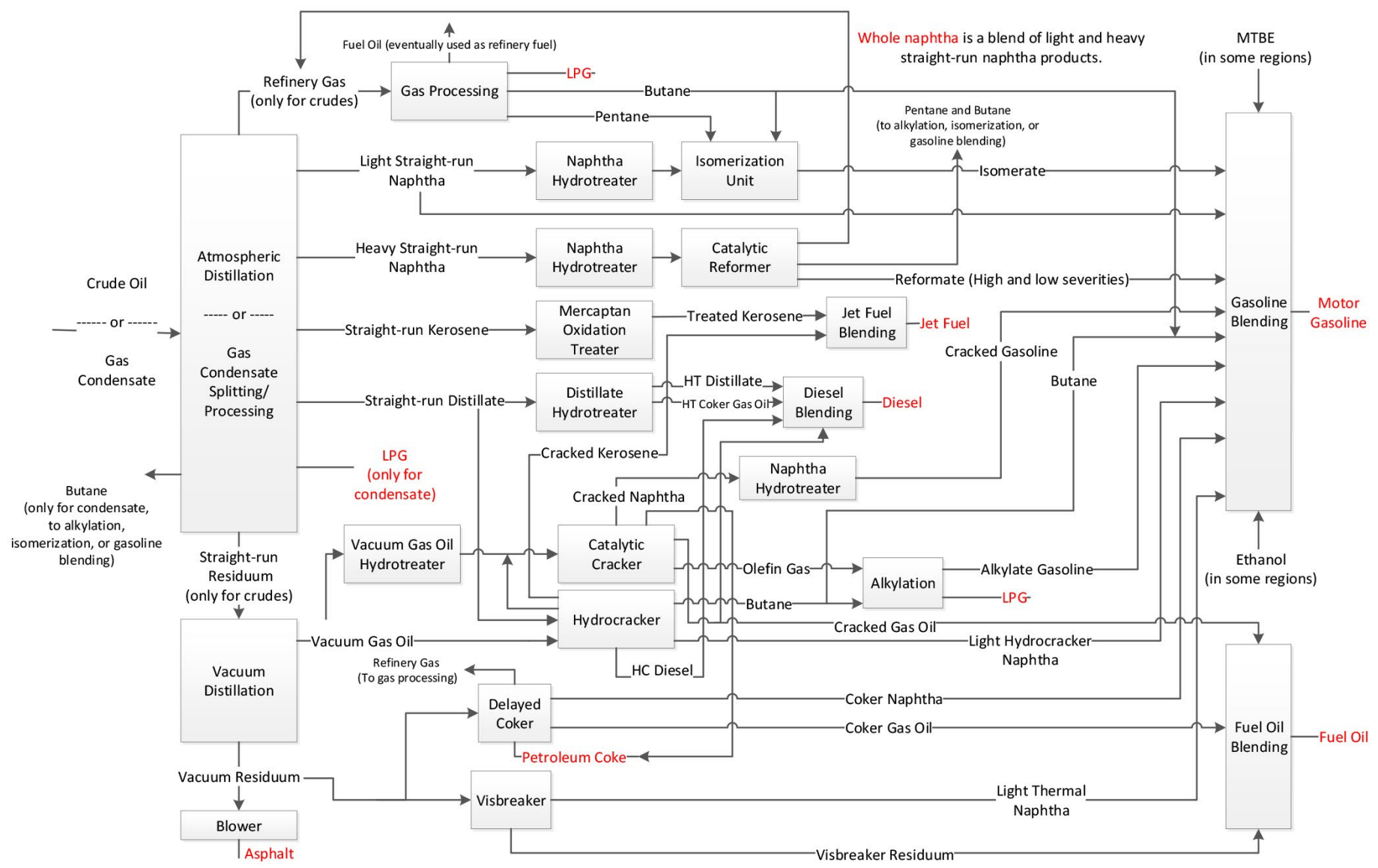

Source: KAPSARC analysis.

Notes: LPG: liquefied petroleum gas; MTBE: methyl tert-butyl ether; HT: hydrotreated; HC: hydrocracked. 
It also includes a constraint that allows us to impose annual capital expenditure limits by region. Relatedly, it varies the discount rate by region to reflect cross-regional differences in risk premiums (Egli, Steffen, and Schmidt 2019). ${ }^{1}$ We add another constraint to stipulate lower bounds for crude oil grade use within individual countries. The model may find that using a specific grade in a particular country that is inconsistent with the available data may negligibly improve the objective function.

Additionally, we formulate each revenue equation by multiplying the regional marginal cost of production by the quantity produced. To maintain a linear formulation, we run several iterations in which the dual variables of finished products' demand constraints are specified as the prices. Thus, we can observe changes in the prices of individual products as the shale oil supply increases. The convergence criteria are that the maximum deviations in the prices and marginal production costs must be below $1 \%$ relative to the previous iteration. ${ }^{2}$ Finally, as Figure 3 shows, we modify the underlying refining structure slightly to account for additional diesel and jet fuel blending streams.

We run the model recursively using two-year horizons from 2017 until 2030. In other words, we perform the optimization by taking into account information about the current and following years. The oil price and other parameters in the second year are treated as long-run attributes. When a solution is obtained, the decisions made in the current year are taken as fixed, whereas the decisions made in the following year may be altered in the next recursive run. For instance, the built capacities in the current year are carried over as fixed capacities in the following year. This horizon choice is sensible because refinery investments are made with reasonable short-run predictions but effectively uncertain long-term information. The initial calibration of the model to reflect 2017 data is detailed in the appendix.

Owing to the 14-year time horizon and the global spatial domain, we use continuous variables throughout the model. Previous analyses with shorter horizons and smaller spatial domains use discrete variables (e.g., Castillo Castillo, Castro, and Mahalec 2017; Karuppiah, Furman, and Grossmann 2008). However, using such features often requires a longer solution time. 


\section{Scenario Descriptions}

his study aims to determine whether a higher shale oil supply will create a mismatch between refineries' capabilities and the demand for oil products. We use a 46 API Eagle Ford crude oil assay as proxy for an average barrel of shale oil. The estimated assay of this Eagle Ford grade is shown in the appendix. We run four scenarios to answer our focal question.

Reference oil supply projections through 2030, as taken from Rystad UCube and described in the appendix.

A $10 \%$ higher supply of U.S. shale oil from 2020 until 2030, represented by a higher Permian shale oil supply, with no capital constraints. This scenario is called More Shale (MS).

Two scenarios in which the supply of Permian shale oil to global markets is $10 \%$ higher from 2020 until 2030 and refineries face capital constraints. Specifically, these scenarios assume that refineries face capital constraints equal to $50 \%$ and $90 \%$, respectively, of the regional annual investments made in the MS scenario starting in 2021. These scenarios are called More Shale, Capital Constrained-50 (MSCC-50) and More Shale, Capital Constrained-90 (MSCC-90), respectively.
For each scenario, we investigate the industry's profits, investment costs and product prices from 2017 to 2030 . Because product demand is exogenous, product prices adjust freely to the changing marginal cost of production as the shale oil supply changes. In practice, however, a lower price of a certain product may induce a higher demand. Thus, the prices suggested by the model are only indicative and are not truly market-clearing. 


\section{Results and Discussion}

he quantitative results presented in this section are based on the many assumptions used by the model. However, they provide some qualitative insights regarding the possible effects of a higher LTO supply on the oil refining sector.

\section{Crude oil intake and refining costs}

Figure 4 shows the amounts of crude oil processed by global oil refineries in each scenario. Figure 5 clarifies the deviations of these oil intakes in the three alternative scenarios relative to the reference scenario. An increase in the supply of lighter shale oil with no capital constraints reduces the quantity of feedstock required to meet the demand for products. Thus, the projected demand for products favors lighter crude grades. As Figure A1 in the appendix shows, fuel oil demand is projected to level off or slightly decline by 2030 . In contrast, the demands for diesel, gasoline and naphtha are projected to grow. The LTO assay, shown in Figure A2, is conducive to this change in product demand.

However, capacity investments are needed to retool existing refineries. With the severe capital constraints in the reference scenario, refineries cannot handle the increased quantity of shale crude oil. The MSCC-50 and MSCC-90 scenarios, in which incremental investment constraints cause the total amount of processed crude oil to rise, support this conclusion. In fact, imposing capital constraints on the MS scenario eventually leads to lower investment expenditures than in the reference scenario. Thus, the crude oil intake in the MSCC-90 scenario is greater than in the reference case in most of the 2020s.

Figure 4. Global annual oil intake by refineries for each scenario.

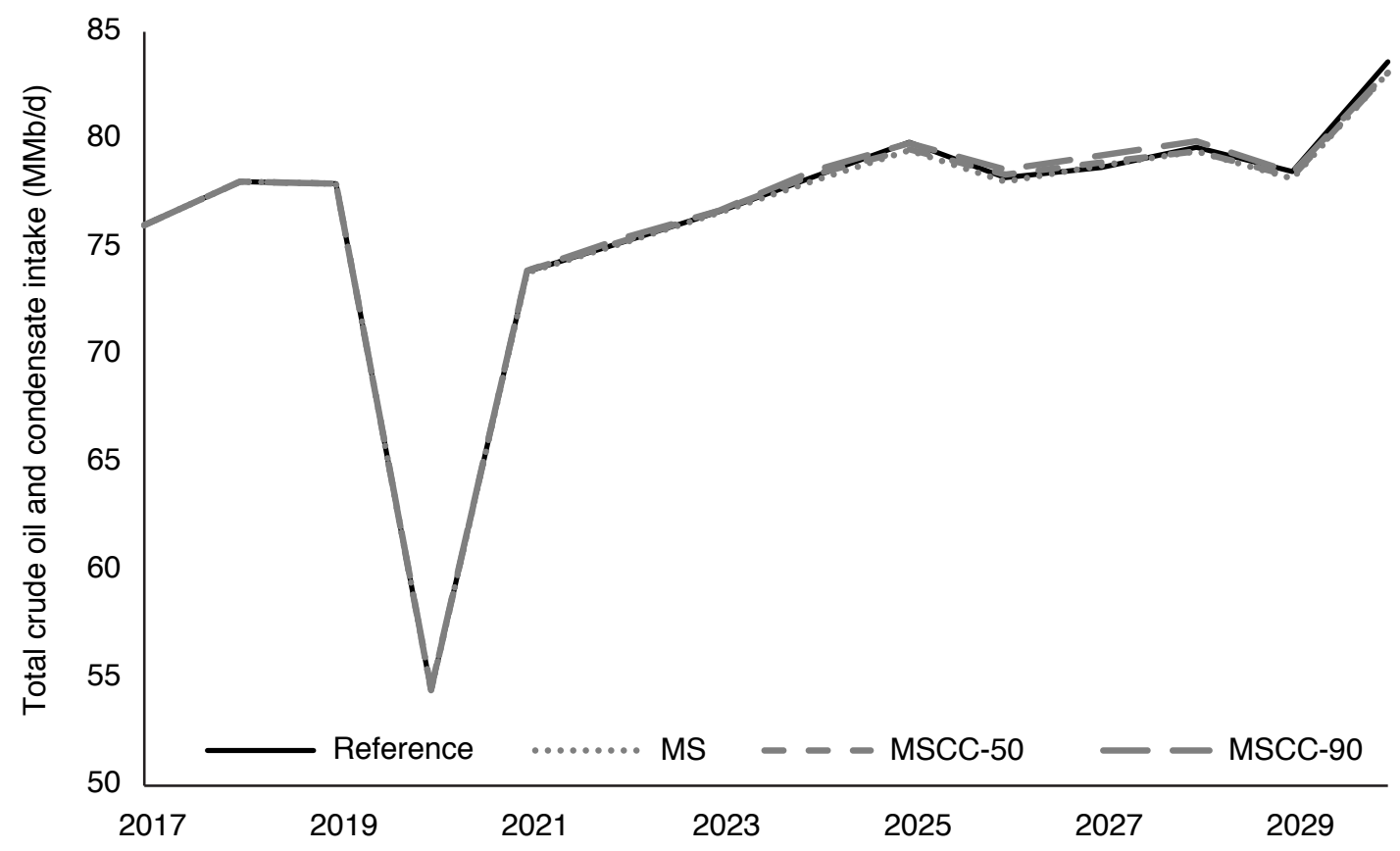

Source: Model results. 
Figure 5. Change in crude oil intake relative to the reference scenario.

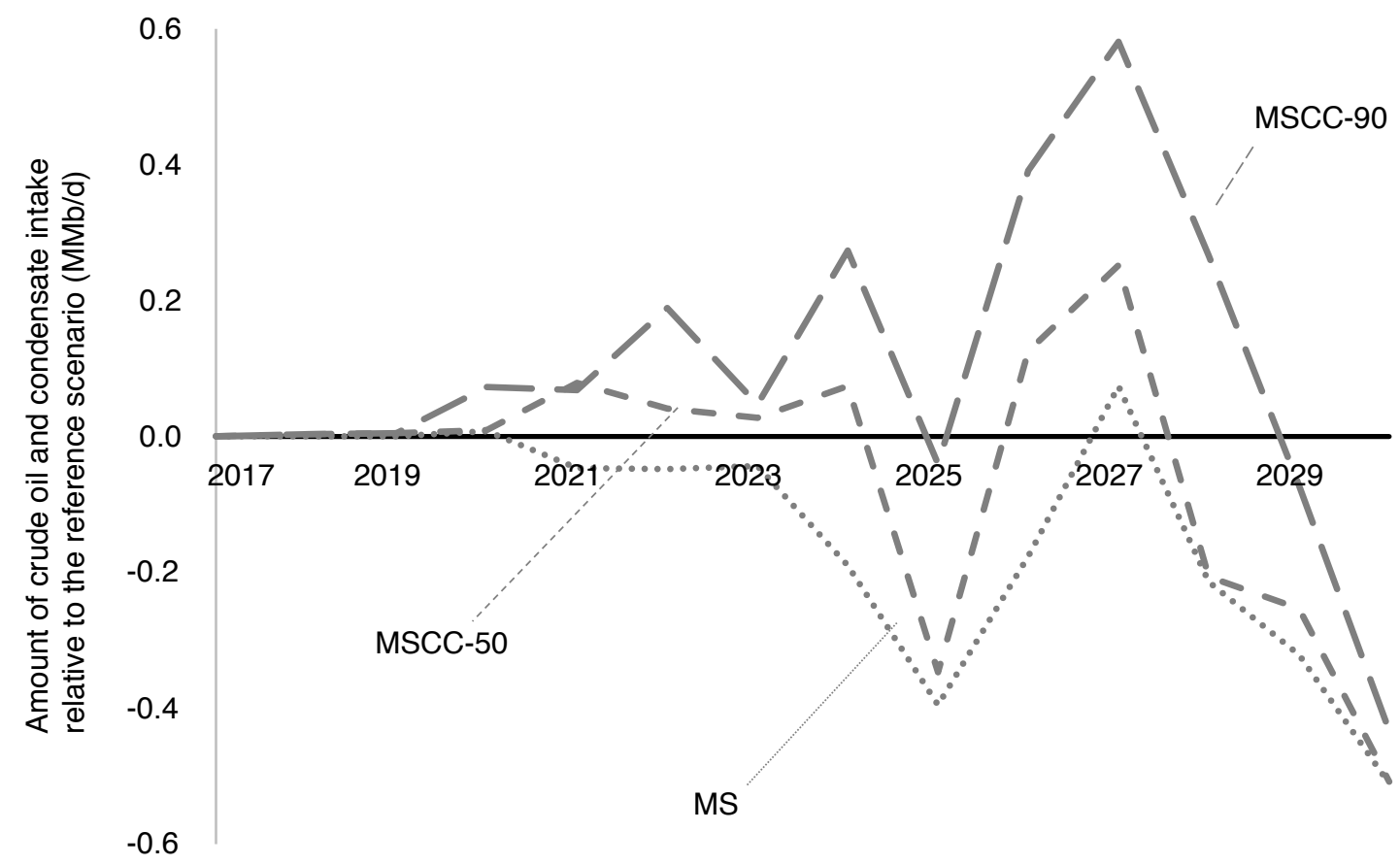

Source: Model results.

Without capital constraints, the total cost to global oil refineries shrinks as the shale supply increases relative to the reference scenario. In all of the scenarios, even those with capital constraints, the shale oil is completely used up. In this context, U.S. LTO is priced lower than many other crude grades in the model. Specifically, it is assumed to always be less expensive than Brent crude oil by $\$ 6.66$ per barrel. This assumption is based on the historical price differential. In any case, it is appropriate for exploring the feasibility of using shale oil in refining. Presumably, if the LTO supply were higher, its price would fall relative to that of Brent crude oil. We explore various price differentials of U.S. LTO with respect to Brent crude oil in the subsequent sections.

Figure 6 shows, however, that as capital is gradually constrained, total annual costs eventually become higher than those in the reference scenario. This result occurs because capital constraints alter the extent to which other, more expensive, crude oil grades are used. For instance, 2027 has relatively large crude oil intake deviations between scenarios, as Figure 5 shows. In the MS scenario, the extra supply of U.S. LTO (API: 46) results in reduced intakes of $\mathrm{CPC}^{3}$ from Kazakhstan (API: 46.6) and gas condensate from Iran (API: 50) in 2027. In the MSCC-90 scenario, in contrast, more total crude oil is used in 2027. The higher volume of U.S. LTO is used with CPC and Iranian gas condensate in conjunction with significantly lower quantities of the heavier Kuwait crude oil (API: 31). CPC and Iranian condensate produce higher quantities of diesel and are more expensive to use relative to Kuwait crude oil. Importantly, these model results are based on exogenous inputs. In practice, parties whose oil is not traded on the market may set their official selling 
Figure 6. Annual change in total global oil refining cost relative to the reference scenario.

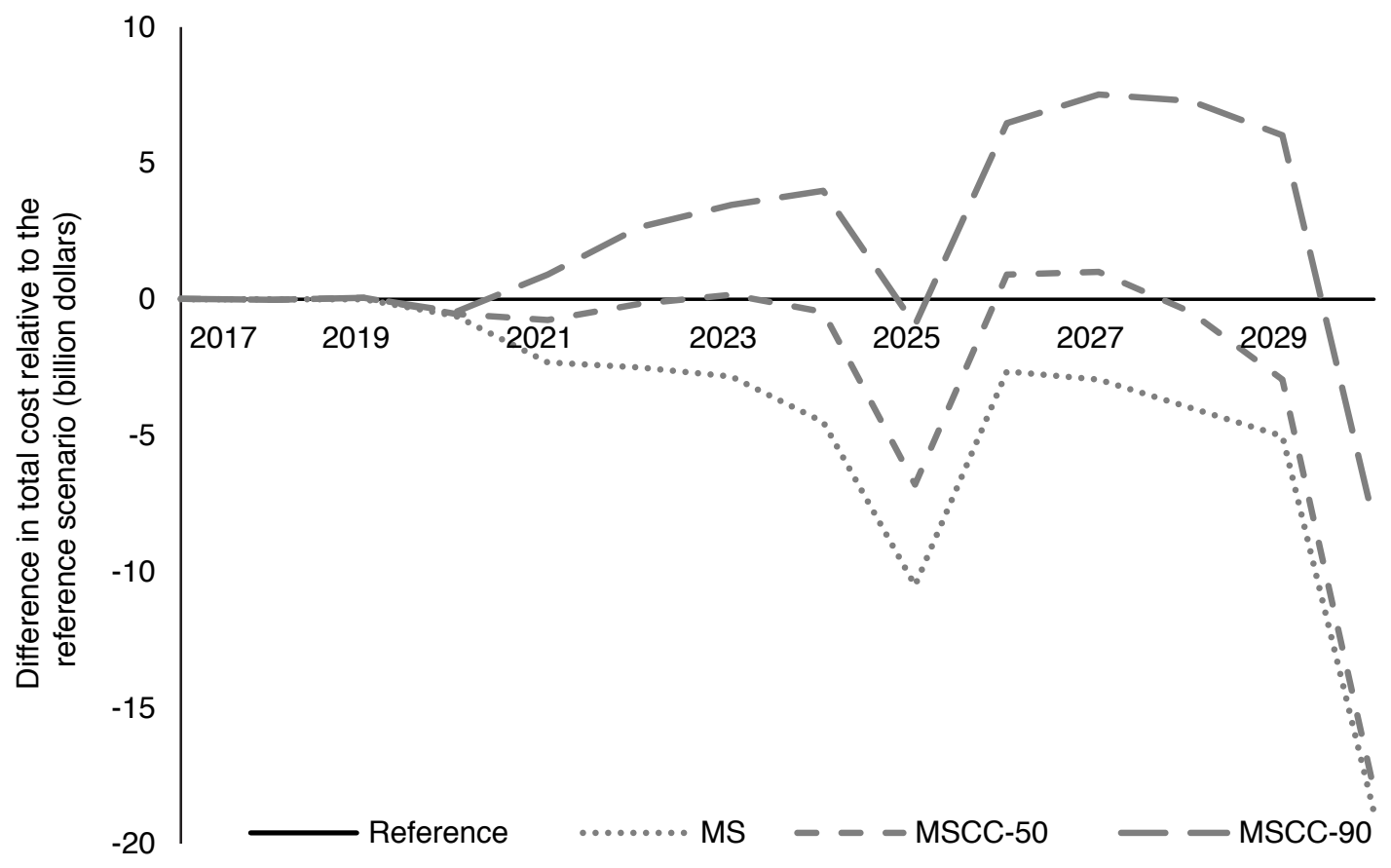

Source: Model results.

Figure 7. Annual share of investment costs in total oil refining costs globally by scenario.

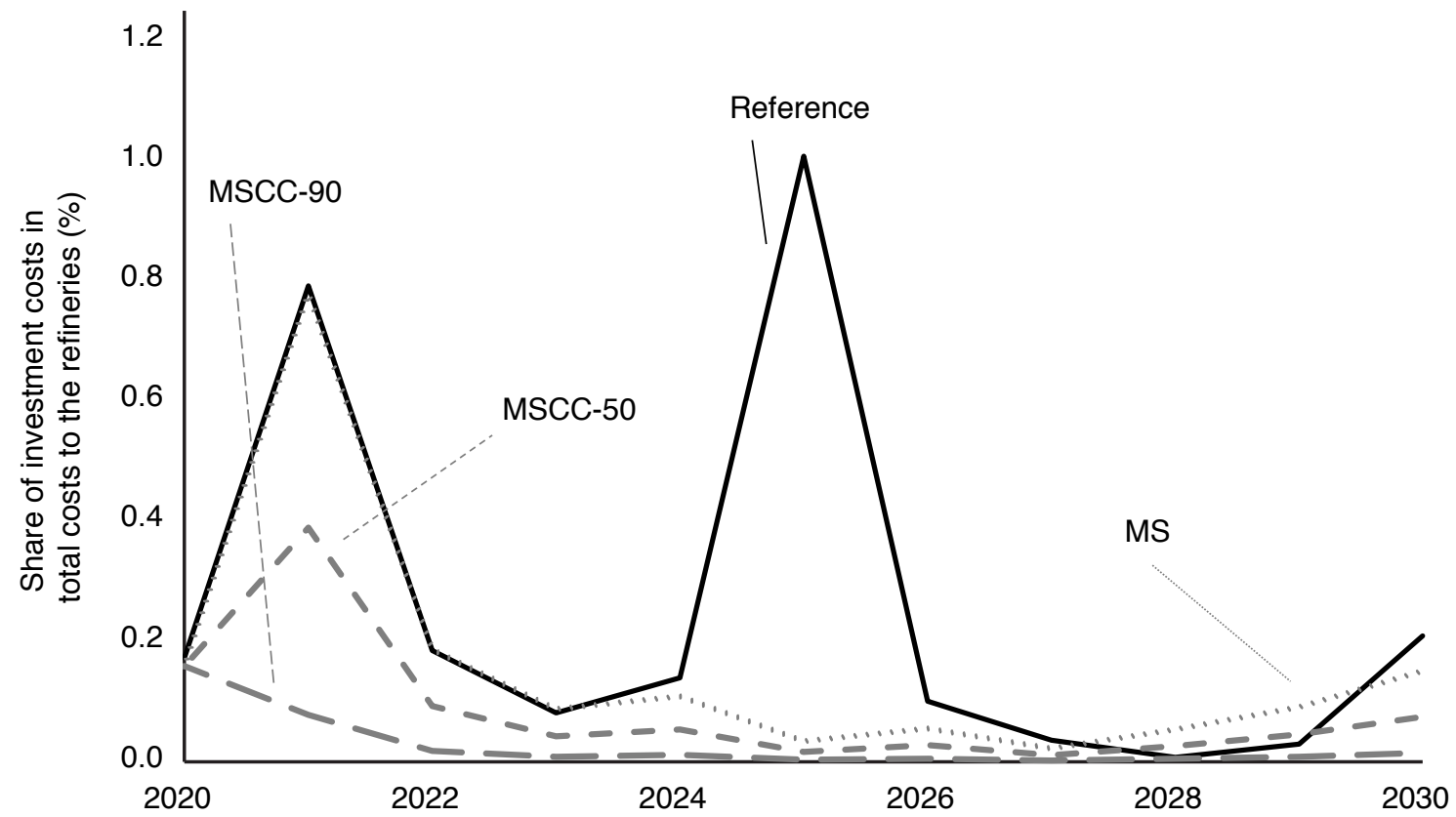

Source: Model results. 
prices aggressively. Such behavior is outside the scope of this analysis.

The lower cost of shale crude oil makes it worthwhile for refineries to invest in the capital needed to process more light crude oil. Figure 7 shows that the share of investment costs in total costs is generally lower in the scenarios with a tighter oil supply relative to the reference case. The spike in investments in the reference scenario coincides with the high marginal costs of producing diesel and fuel oil in 2025. These high costs are alleviated in subsequent years, as large investments in hydrocracking capacity are made in 2025 and 2026 in this scenario.

Table 1 summarizes the required capital expenditures by refineries in each scenario. Globally, investments in oil refineries are generally lower in the MS scenario than in the reference scenario between 2020 and 2030. Capital expenditures in the U.S. fall by a billion dollars in the MS scenario. They decrease even more in Australasia but fall to a lesser extent in Europe and Latin America. The forgone investments in Australasia are primarily in atmospheric and vacuum distillation capacities. Europe reduces its investments in gas condensate splitters. In the scenarios with capital constraints, the limits on capital expenses begin in 2021. Refineries are not pressed to expand capacity to keep up with the demand because the demand projections are lower.

In the reference scenario, investments spike in two years: 2021 and 2025. Those spikes occur owing to the recovery of product demand in 2021 and the high marginal costs of producing diesel and fuel oil in 2025. In 2025, catalytic cracking capacity is added. The capacity of hydrocracking units also increases in the former Soviet Union, North America, Latin America and the Middle East to meet the rising demand for diesel. As Figure 3 shows, hydrocrackers yield some diesel that is blended with other distillates in developing the finished product. In addition, refineries in Australasia also invest in atmospheric distillation capacity, helping reduce the marginal costs of diesel and fuel oil in 2025.

The share of capital investments is lower than in the reference scenario even when capital constraints are tightened to $10 \%$. Crude purchasing operations make up the largest share of these costs. This result is because, as capital constraints tighten with a greater LTO supply, refineries use larger quantities of heavier crudes to blend with the LTO and invest less than in the reference scenario.

Table 1. Refineries' cumulative 10-year investment requirements in each scenario.

\begin{tabular}{l|l|c} 
Scenario & \multicolumn{1}{|c}{ Description } & $\begin{array}{c}\text { Cumulative global refining investments from } \\
\text { 2020 to 2030 (real 2017\$) }\end{array}$ \\
\hline Reference scenario & Using Rystad supply projections as of April 2020 & \$46 billion \\
\hline MS & $\begin{array}{l}\text { U.S. LTO output increases 10\% over the reference } \\
\text { case scenario }\end{array}$ & \$27 billion \\
\hline MSCC-50 & $\begin{array}{l}\text { Refineries' capital investments are constrained by } \\
50 \% \text { relative to the MS scenario }\end{array}$ & \$14 billion \\
\hline MSCC-90 & $\begin{array}{l}\text { Refineries' capital investments are constrained by } \\
90 \% \text { relative to the MS scenario }\end{array}$ & $\$ 3.8$ billion
\end{tabular}




\section{Product prices}

In this analysis, product prices are set equal to their marginal costs of production and shipping. Figures 8 to 10 show that these prices rise over time as demand recovers following COVID-19, mainly because crude oil prices rise gradually until 2030. Figure 8 also shows the projected Brent crude oil prices that we use to visually highlight the correlation between gasoline and crude oil prices. Additionally, the figures show the effects of a greater shale oil supply on the prices of gasoline, diesel and naphtha in North America. The more prevalent use of LTO has no clear downward or upward impact on product prices across all products and years. The prices are representative in other regions so that the model does not result in interregional transport.

In the reference scenario, the marginal cost of diesel rises to nearly $\$ 3,100$ per tonne in 2025 . However, this sharp rise does not occur in this scenario if we use the crude oil supply and product demand assumptions before COVID-19 as inputs (i.e., if we omit the demand decline in 2020). This increase in diesel costs may not occur owing to the many confluent factors that affect oil markets and refineries' sub-annual mitigation response. Nevertheless, it implies that lower investments in refining capacity and the demand response following COVID-19 recovery can cause distillate prices to surge five years later. The lower product demand in 2020 causes underinvestment in the model given its two-year optimization horizon. This horizon means that for each year, the model only considers information on product demand for the next two years. The resulting lower investment triggers a sharp rise in diesel prices in 2025 as demand rises.

Figure 8. Annual gasoline prices in North America by scenario.

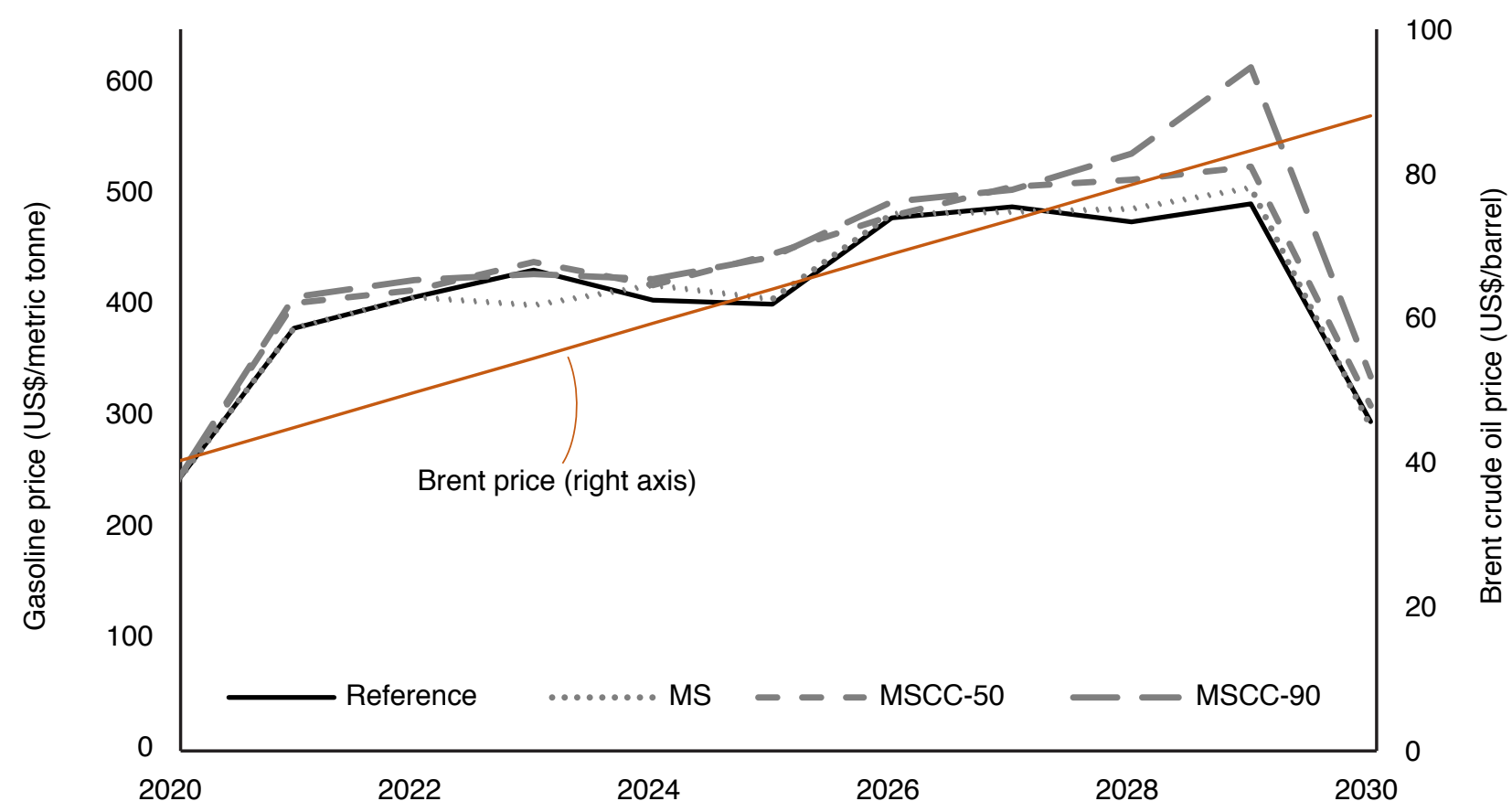

Source: Model results. 
Figure 9. Annual diesel prices in North America by scenario.

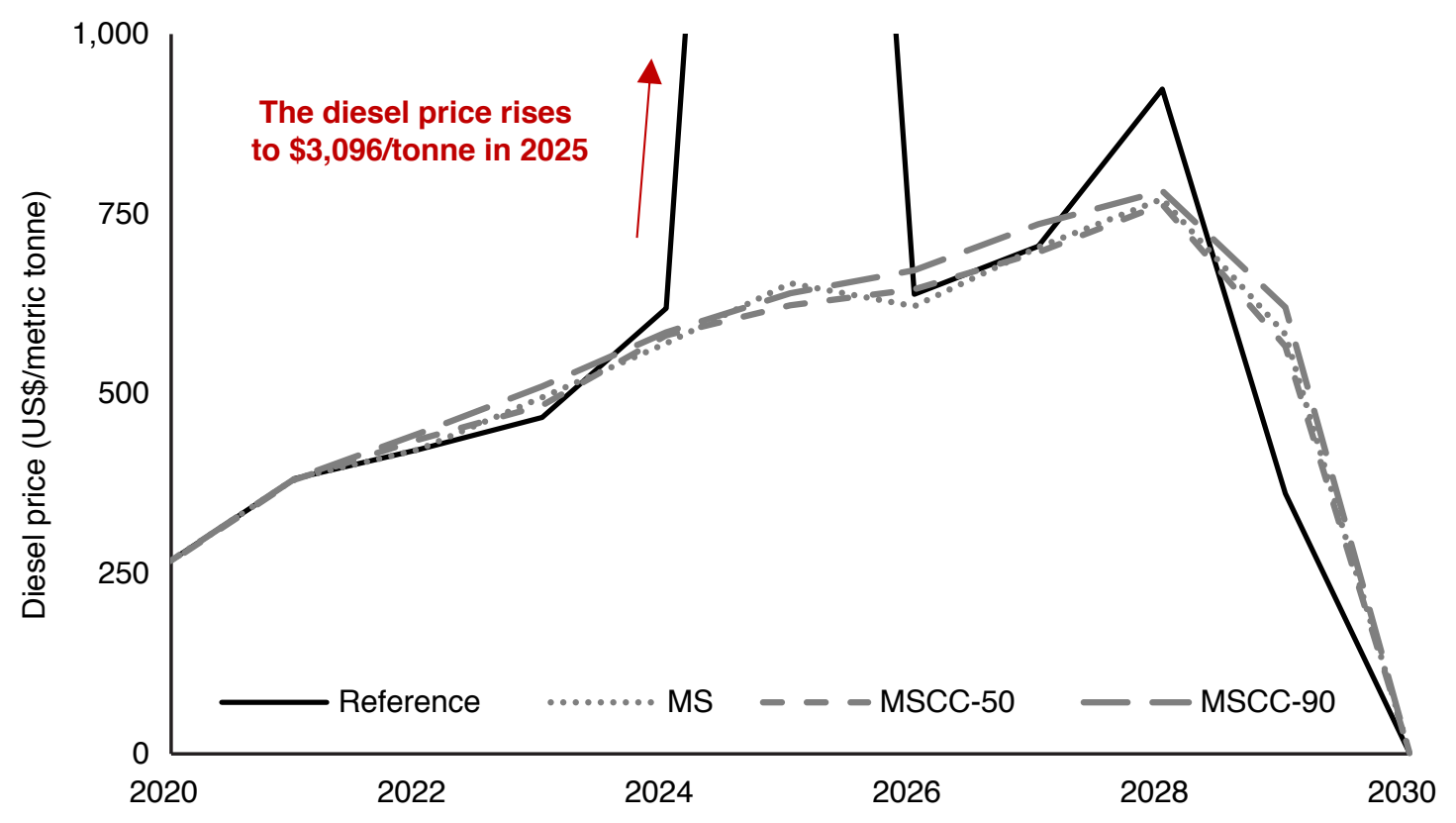

Source: Model results.

Figure 10. Annual commercial naphtha prices in North America by scenario.

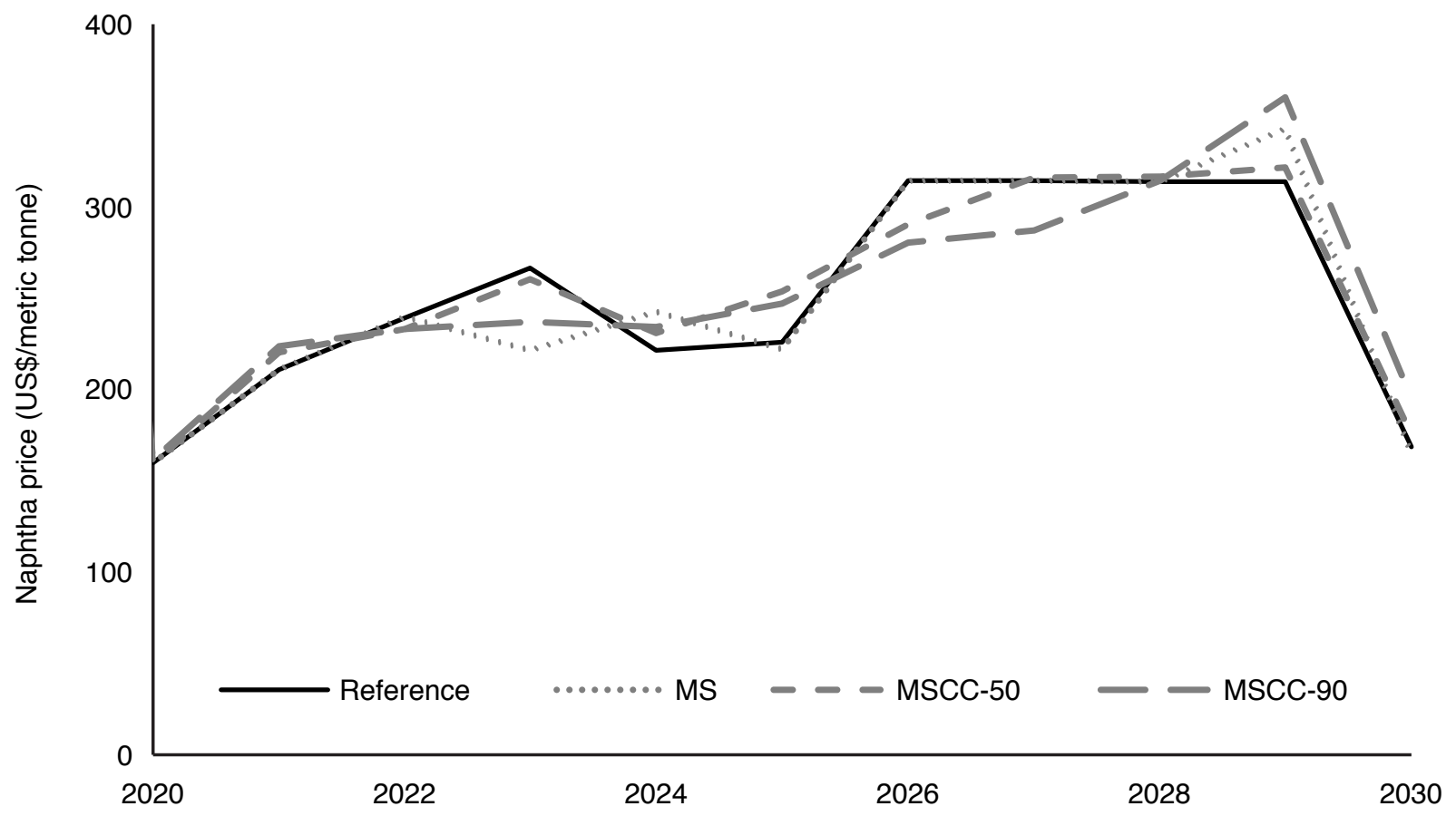

Source: Model results. 
The prices decline at the end of the time period because of end of period effects, especially for diesel. In 2030, the model is run as a single long-run year model with completely annualized investment costs, whereas two-year optimization horizons are used in the previous years. Only the second year of the recurrent optimization uses fully annualized investment costs in this case.

To further show the impact of a greater shale oil supply, Figure 11 displays the annual relative average gross refining margin (GRM) in the MS scenario by region. The GRM is simply defined as the difference between the weighted average price of the produced fuels and the refineries' weighted average cost of crude oil. The averages are weighted by quantity, and the relative average GRM is found by subtracting the GRM in the reference scenario from that in the MS scenario. A negative (positive) relative GRM indicates that the refineries have a lower (higher) GRM than in the reference case. The sharp drop in 2025 is entirely explained by the high diesel price in that year in the reference scenario, as Figure 9 shows. A greater supply of LTO generally reduces the GRM. However, we do observe exceptions in some regions in some years, such as the Far East in 2026 and 2027 and the Middle East in 2030.

Figure 11. GRM by region in the MS scenario relative to the reference scenario.

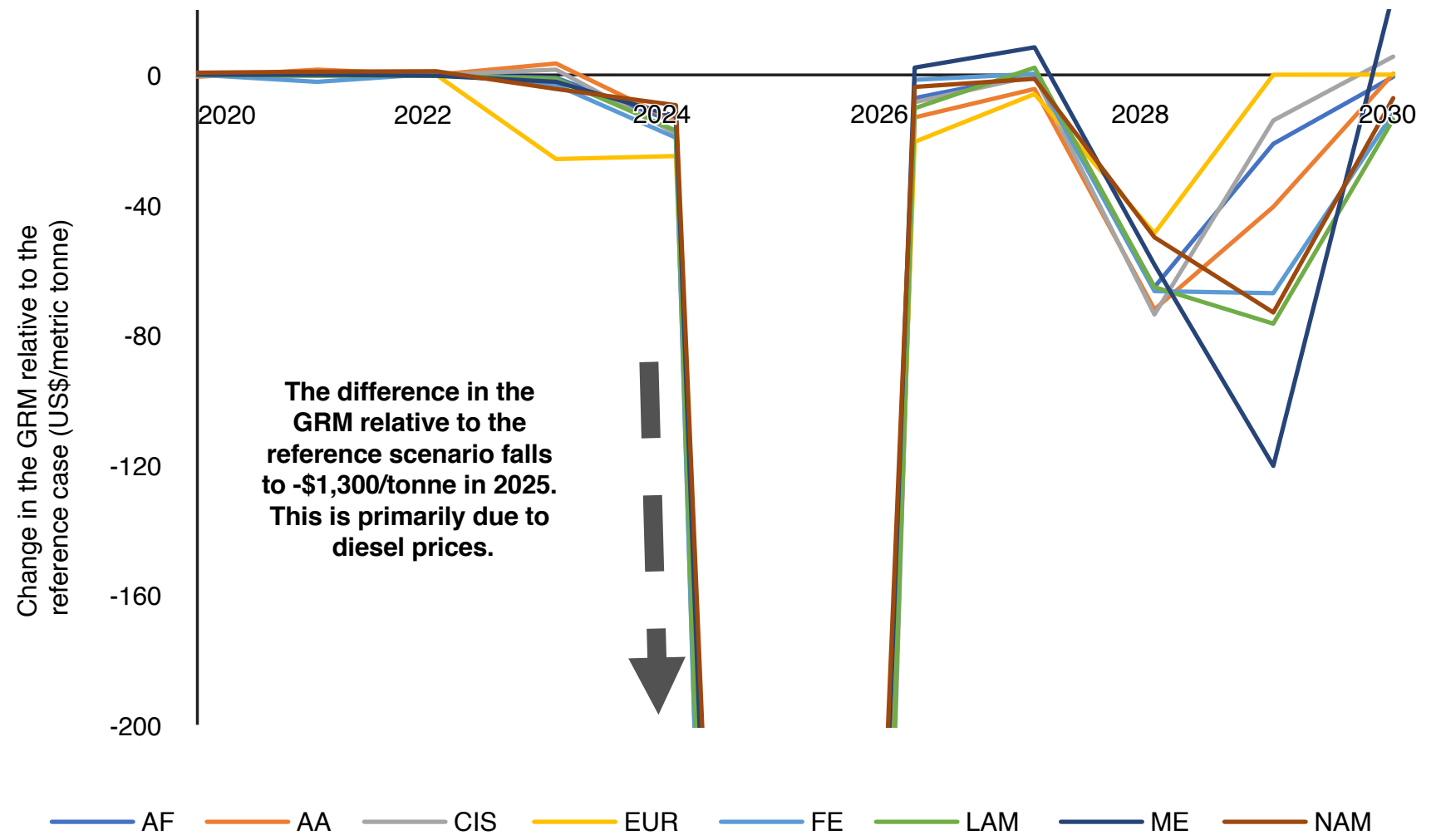

Source: Model results. 


\section{Sensitivity of the results to the U.S. LTO discount relative to Brent crude oil}

As stated, U.S. LTO is discounted by $\$ 6.66$ per barrel relative to Brent crude oil in the main scenarios. We make this assumption to encourage the use of the increased shale oil supply to answer the focal question of this study. However, we also lower the discount to examine the effects of different discounts on the main results. Figure 12 shows the intake of LTO originating from the U.S. in the MS scenario for different LTO prices. We illustrate the MS scenario to observe the effects of a higher shale oil price in conjunction with a greater shale oil supply. Price spreads above $\$ 5$ or $\$ 10$ per barrel are unrealistic. However, Figure 12 includes them to highlight the extent to which U.S. LTO must cost more than Brent crude oil to incur its removal.

When LTO is at parity with Brent crude oil, the refinery intake only declines in 2020 because of the presumed drop in oil demand due to COVID-19. The shale oil price premium relative to Brent crude oil must exceed \$5 per barrel to observe some material reduction in its use. Thus, feedstock costs are a more pressing issue than the quality of shale oil. By 2030 , however, product demand is sufficiently high so that all available shale oil is used regardless of the price premium.

Figure 12. Intake of U.S. shale oil in the global oil refining system for different prices of U.S. LTO in the MS scenario.

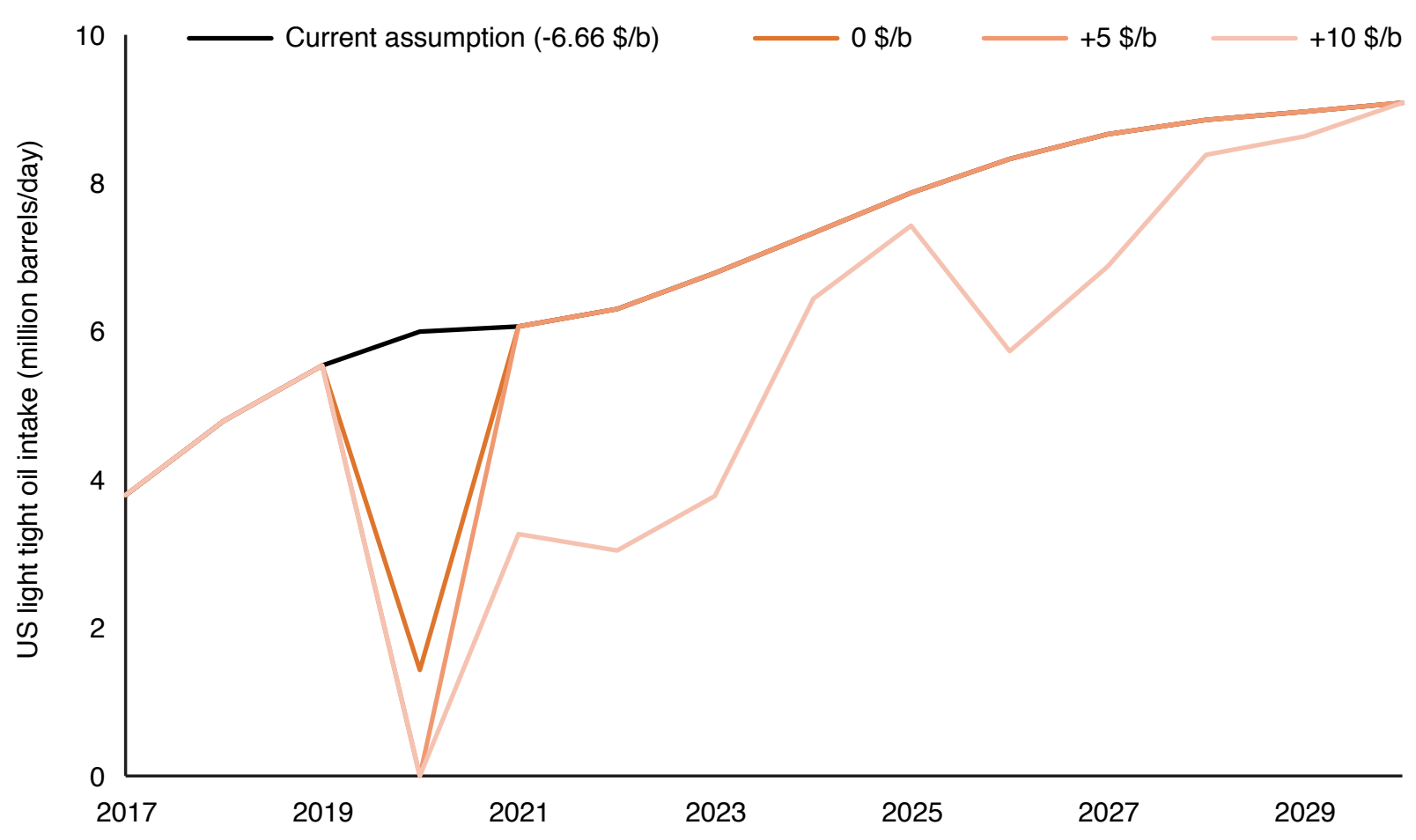

Source: Model results. 


\section{Results and Discussion}

The marginal cost of gasoline more than doubles when the discount is cut to $\$ 3$ per barrel during the horizon, as does its price. However, it stabilizes from that point until the price of U.S. LTO is $\$ 10$ per barrel higher than that of Brent crude oil. The prices of diesel and fuel oil do not change as the price differential between LTO and Brent crude oil goes from $-\$ 6.66$ per barrel to $+\$ 5$ per barrel. However, the marginal costs of both products almost double as the differential increases to $+\$ 10$ per barrel.

\section{Other considerations}

The aforementioned results consider a modestly (10\%) higher supply of LTO in conjunction with other crude oil grades. To test the model at its extreme, we also examine a set of inputs that only considers the shale oil supply originating from the U.S. In this extreme example, the shale oil supply hypothetically reaches over $100 \mathrm{MMb} / \mathrm{d}$ from 2020 to 2030, and the supplies of all other crude grades are set to zero. In this case, the model becomes infeasible starting in 2019, the year in which 2020 data are incorporated into the analysis. This result highlights the inadequacy of using only shale oil to satisfy the slate of refined oil products described in the appendix.
This analysis suggests that quality does matter to some extent. However, if sufficient amounts of heavier crude grades are available for blending, a greater supply of shale oil is not a problem. Nevertheless, technical challenges can arise in blending light and heavy crude oil. These challenges can increase refineries' maintenance costs and offset the benefits of purchasing low-cost crude oil. These challenges arise when incompatible blends are created by mixing heavy crude oils, which have high asphaltene contents, with paraffinic LTOs. Such mixing can cause asphaltene instability, which can create sludge buildup in crude tanks and damage downstream processing equipment (Garret et al. 2016). Our model does not account for the impacts of these limitations on refineries adapting to increased volumes of U.S. LTO. However, this consideration can be an area for further research.

For full disclosure, we also tested a lower demand outlook for oil products assuming a far slower recovery from COVID-19 in terms of energy use. With these assumptions, the initial refining capacity is sufficient to handle the projected crude oil supply without meaningful investments. 


\section{Conclusion}

his study aimed to determine whether oil refineries can adjust to a greater supply of

LTO. To do so, we modified a custom-built oil refining optimization model from the multi-sector KAPSARC Energy Model. We ran the model from 2017 until 2030 using a two-year optimization horizon. Thus, investment and operational decisions were based on the model inputs over the next two years. This assumption takes into account an element of bounded rationality. The model incorporated around 100 crude oil grades and their corresponding assays and divided the world into eight regions. Inter-regional trade of both crude oil and oil products was permitted.

Overall, this study shows that oil refineries can handle the quality of a greater supply of LTO. Given Rystad's future LTO supply projections, oil refineries adjust by investing primarily in atmospheric distillation and hydrocracking capacity. Total full-cost investments from 2020 to 2030 are $\$ 46$ billion in 2017 dollars. Without capital constraints, a 10\% rise in the LTO supply relative to the Rystad projections reduces the crude oil refining intake between 2020 and 2030. This result suggests that the product yields of LTO are better matched with the demanded products. Thus, less investment in atmospheric distillation is needed. In this case, total investment costs from 2020 until 2030 approach $\$ 27$ billion in 2017 dollars.
We also considered scenarios in which the LTO supply is greater than the Rystad projections and refineries are severely capital constrained. In this case, refineries use larger quantities of other grades that produce less straight-run distillate to blend with LTO. The capital constraints therefore increase operations costs stemming from the purchase of more feedstock. Refineries also reduce their investments in these scenarios relative to the reference scenario. Oil refineries can therefore achieve further cost reductions through lower crude purchasing costs if they have access to the necessary capital. In our main scenarios, we generally did not observe large deviations in products' prices owing to the advent of a greater shale oil supply.

Relative feedstock prices are the main determining factor for LTO use. Our model assumes that LTO is priced below Brent crude oil. If the LTO and Brent crude oil prices are at parity, LTO's use is only lower in 2020, when product demand dips. Thus, LTO must be much more expensive than Brent crude oil to be neglected over the analysis horizon. Of course, LTO alone is inadequate to meet the demand for refined oil products. The analysis therefore suggests that quality does matter. However, if heavier crude grades are sufficiently available for blending, higher shale oil supply is not an issue. 


\section{Endnotes}

${ }^{1}$ Egli, Steffen, and Schmidt (2019) show that the risk premium ranges from $0 \%$ to $22.1 \%$ across the world, with the highest values in African countries.

${ }^{2}$ Although we can solve the model as a mixed complementarity problem (MCP) without iterating, the iterative optimization route solves much more quickly than a single MCP attempt does.

${ }^{3} \mathrm{CPC}$ refers to the Caspian Pipeline Consortium. 


\section{References}

Alhajji, Anas. 2018. "An Energy Crisis Looms as Forecasts Ignore US Shale Quality." Financial Times, December 13. Accessed May 17, 2020. https://www.ft.com/content/ d4a8c0ea-f8ad-11e8-8b7c-6fa24bd5409c.

Alkathiri, Nader, Yazeed Al-Rashed, Tilak Doshi, and Frederic H. Murphy. 2017. "'Asian Premium' or 'North Atlantic Discount': Does Geographical Diversification in Oil Trade Always Impose Costs?" Energy Economics 66:411-20. DOI: 10.1016/j. eneco.2017.07.005

BP. 2018. BP Statistical Review of World Energy. Sheet in the Excel file: Oil Inter-area movements.

- - . 2019. "Crude Assays." Accessed September 19. https://www.bp.com/en/global/bp-global-energytrading/features-and-updates/technical-downloads/ crudes-assays.html.

Castillo Castillo, Pedro, Pedro M. Castro, and Vladimir Mahalec. 2017. "Global Optimization Algorithm for Large-Scale Refinery Planning Models with Bilinear Terms." Industrial and Engineering Chemistry Research 56(2):530-48. DOI: 10.1021/ acs.iecr.6b01350

Ceric, Emir. 2001. Crude Oil Assay. Emir Ceric. ISBN: 9539777046.

Crude Oil Monitor. 2019. Accessed September 19, 2019: www.crudeoilmonitor.ca.

Egli, Florian, Bjarne Steffen, and Tobias S. Schmidt. 2019. "Bias in Energy System Models with Uniform Cost of Capital Assumption." Nature Communications 10(1):1-3. DOI: 10.1038/ s41467-019-12468-z
Eni. 2020. "World Oil Review 2019." January 19. Accessed June 30, 2020. https://www.eni.com/ assets/documents/documents-en/WORLD-OILREVIEW-2019-Volume-1.pdf.

U.S. Energy Information Administration (EIA). 2015. "Technical Options for Processing Additional Light Tight Oil Volumes within the United States."

- - . 2018. "Liquid Fuels Market Module of the National Energy Modeling System: Model Documentation 2018." 7, 27-36.

-- - 2020. "Annual Energy Outlook 2020: With Projections to 2050." 31, 48, 52.

Equinor. 2019. "Crude Oil Assays." Accessed September 19, 2019. https://www.equinor.com/en/ what-we-do/crude-oil-and-condensate-assays.html.

ExxonMobil. 2019. "Assays Available for Download." Accessed September 24, 2019. https://corporate. exxonmobil.com/Crude-oils/Crude-trading/ Assays-available-for-download.

Garret, Thomas, Patrick Christensen, William Vukovich, and Thomas Yeung. 2016. "The Challenges of Crude Blending - Part 2." Digital Refining. Accessed May 13, 2020. https://www. digitalrefining.com/article/1001276,The_challenges_ of_crude_blending___Part_2.html\#.XrRh554zapp.

Gary, James H., and Glenn E. Handwerk. 2001. "Petroleum Refining: Technology and Economics. Fourth Edition." New York: Marcel Dekker Inc., 85-86. DOI: 10.1201/9780824745172

International Energy Agency (IEA). 2018a. "World Energy Model Documentation: 2018 Version." 
- - . 2018b. "Oil Market Report: Annual Statistical Supplement with 2017 Data." 9-11, 14.

- - . 2019a. "World Energy Outlook 2019." 132, 143. DOI: $10.1787 /$ caf32f3b-en

- - . 2019b. "World Energy Statistics." https:// www.iea.org/data-and-statistics?country=WORLD\&f uel=Oil\&indicator=CrudelmportsExports

- - . 2019c. "World Energy Prices: An Overview." 10.

- - - 2020. "World Energy Investment 2020." May. Accessed June 7, 2020. https://www.iea.org/reports/ world-energy-investment-2020.

KAPSARC. 2016. "The KAPSARC Energy Model for Saudi Arabia: Documentation of the Model Build Called 'KEM-SA_v9.16'.'Accessed October 28, 2020: https://www.kapsarc.org/wp-content/ uploads/2016/11/KEM-SA_documentation_v9.16.pdf.

Karuppiah, Ramkumar, Kevin C. Furman, and Ignacio E. Grossmann. 2008. "Global Optimization for Scheduling Refinery Crude Oil Operations." Computers and Chemical Engineering 32(11):274566. DOI: 10.1016/j.compchemeng.2007.11.008

Kemp, John. 2014. "U.S. Refiners Struggle with Too Much Light Crude." Reuters. June 2. Accessed May 10, 2020. https://www.reuters.com/article/usa-oilexports-kemp/column-u-s-refiners-struggle-with-toomuch-light-crude-kemp-idUSL6N0OJ3W520140602.

Lantz, Frédéric, Valérie Saint-Antonin, Jean-François Gruson, and Wojciech Suwala. 2012. "The OURSE Model: Simulating the World Refining Sector to 2030." European Commission. JRC Scientific and Technical Reports.
Petrosyan, Kristine. 2018. "Quality vs Quantity Are Global Refiners Ready for US Shale Exports?" International Energy Agency. May 7. Accessed June 19, 2020. https://www.iea.org/commentaries/qualityvs-quantity-are-global-refiners-ready-for-us-shaleexports.

Renewable Fuels Association (RFA). 2019. "2019 Ethanol Industry Outlook." 11.

Sheppard, David. 2018. "Will US Shale Give the Refining Industry Indigestion?" Financial Times. March 13. Accessed May 17, 2020. https://www.ft.com/ content/2e7f9964-21f8-11e8-add1-0e8958b189ea.

Thakur, Amit Kumar, and Ajay Kumar Kaviti. 2018. "Progress in Regulated Emissions of Ethanol-Gasoline Blends from a Spark Ignition Engine." Biofuels 8(1):1-24. DOI: 10.1080/17597269.2018.1464875

Total Oil Trading SA. 2019. "Crude Assays." Accessed September 19, 2019. http://www.totsa. com/pub/crude/crude_assays.php?rub=1.

Treese, Steven A. 2015. "Selection of Crude Oil Assays for Petroleum Refining." Handbook of Petroleum Processing, 1-33. DOI: 10.1007/978-3-319-05545-9_34-1

UN Conference on Trade and Development. 2010. "Oil Prices and Maritime Freight Rates: An Empirical Investigation." UNCTAD/DTL/TLB/2009/2. 


\section{Appendix - Data inputs in the oil refining model and model validation}

\section{Data inputs}

This section details the data acquisition and processing steps used to calibrate the model to 2017. We obtain regional refining unit capacities from the IHS Markit Midstream database. We adopt the IHS'S regional breakdown of the world for the remaining data sets. This breakdown is as follows: North America, Latin America, Far East, Former Soviet Union, Australasia, Europe, Middle East and Africa. However, we move India, Pakistan, Indonesia, Bangladesh, Vietnam, Thailand, Sri Lanka, Singapore, the Philippines and Malaysia from the Far East to Australasia. Thus, these countries are included with the Oceanic countries, and China, Japan and the Korean peninsula comprise the Far East. We make this change so that the regions are in line with the IEA's demand data.

Additionally, we use the IEA's World Energy Outlook (WEO) (IEA 2019a) for the regional demand projections of the various refined oil products. The WEO contains only global demand for certain years; thus, we must make two assumptions. First, we assume that the regional demand shares of refined products in 2017 remain the same through 2030. The IEA's (2018b) Annual Statistical Supplement, which is published alongside its Oil Market Report, allows us to estimate a regional breakdown of the demand for refined products in 2017. Second, we make linear interpolations between the years for which the WEO provides regional projections.

Figure A1. Global product demand projections until 2030.

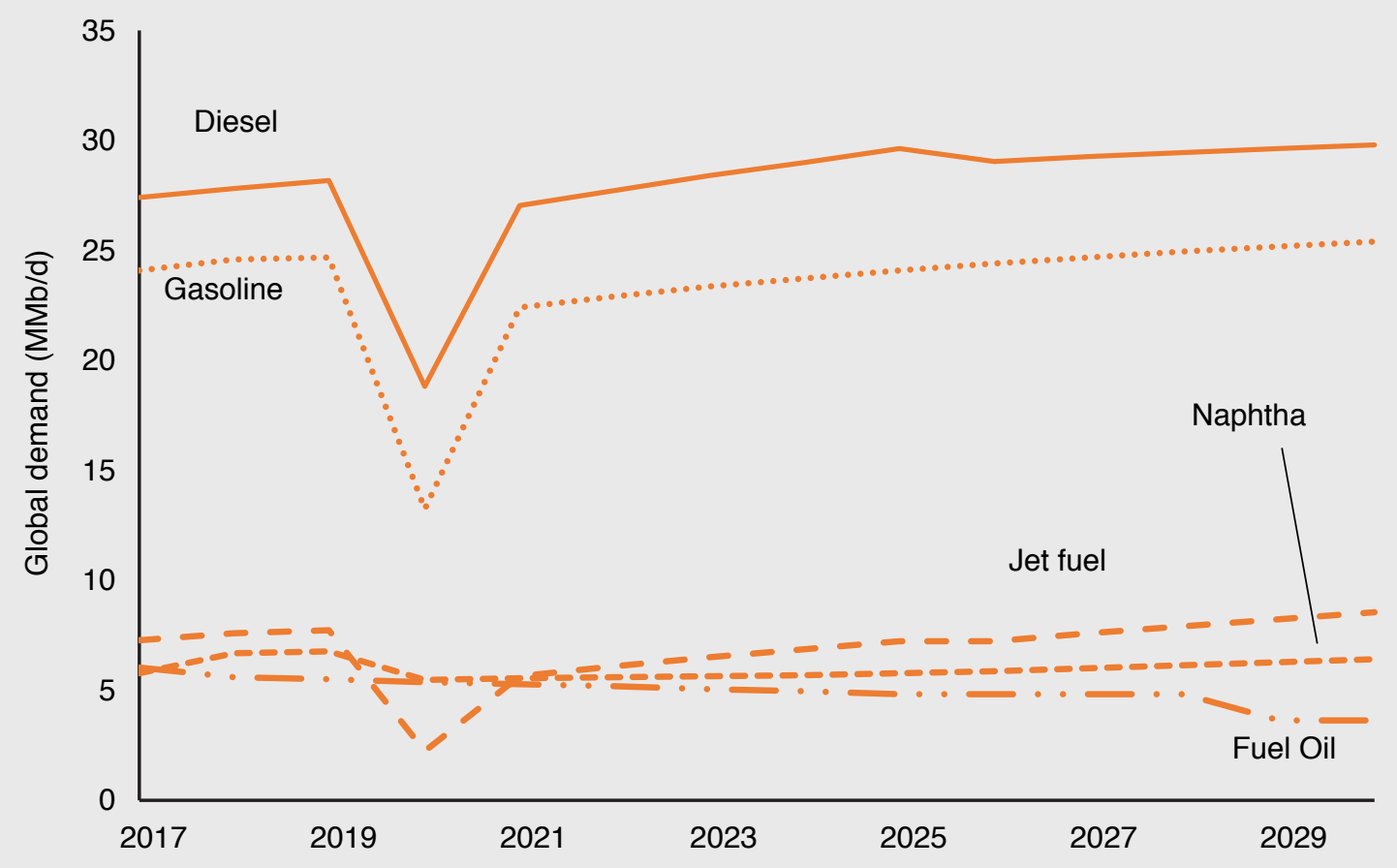

Source: Authors' analysis. 
Owing to the global outbreak of COVID-19 in 2020, we adjust the resulting demand projections at the global scale, as shown in Figure A1. Figure A1 does not show the projections for asphalt, petroleum coke or liquefied petroleum gases to avoid cluttering. Jet fuel takes the largest hit in 2020, followed by gasoline; other products are less impacted. Then, we reduce our downward adjustments to the IEA's (2019a) projections over time such that demand recovers to equal these projections by 2030. We surmise that the adjusted demand projections for jet fuel, gasoline and diesel create an italic V-shaped recovery.

For the crude oil supply, we use IEA (2019b) data to identify the countries of interest. The 30 countries with the highest production levels captured over $94 \%$ of the crude oil market in 2017 . The remaining production in each region is classified as "other production," and representative grades are used. We assign grades to each of the 30 countries based on API gravities using the Rystad UCube software package. We use a total of around 100 grades in the model. The crude oil grades are mostly blended crude oil with varying attributes, such as API gravity and sulfur content.

We use Rystad's supply projections published on April 20, 2020 to incorporate their post-coronavirus perspective. The Rystad projection data shown in Figure A2, which complement Figure 1, indicate that most new production in the U.S. after 2019 is expected to have an API gravity above 40. The EIA (2020) states that the greatest growth in the crude oil supply will occur in the Permian region of the U.S. Thus, we consider Eagle Ford crude oil (API: 46.6) or West Texas Light $(44<\mathrm{API}<50)$ to be representative of that growth.

Figure A2. Rystad projections for the U.S. crude oil supply after 2019 by API gravity.

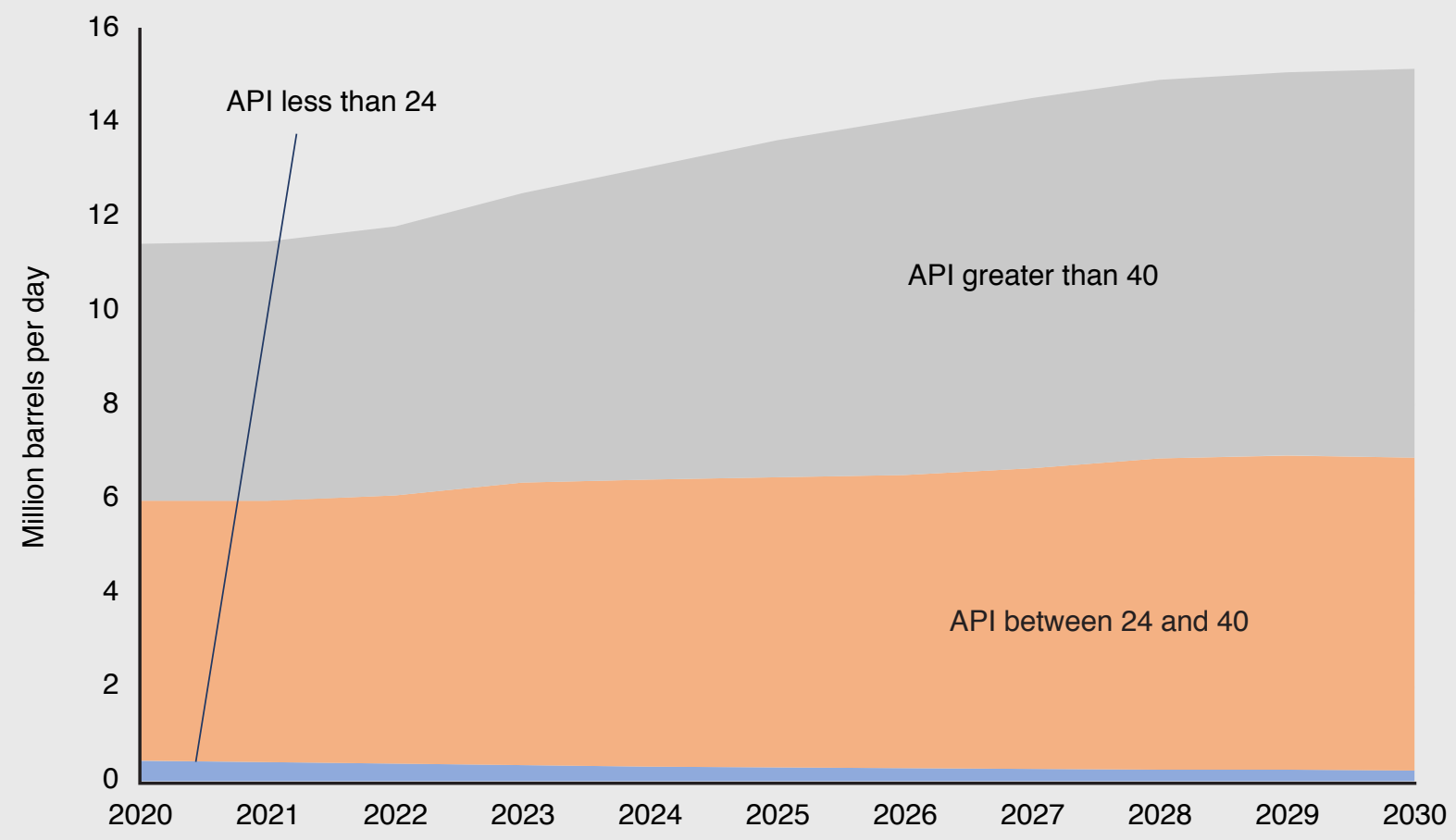

Source: Rystad UCube. 
Then, we gather crude oil assays for each grade from several freely accessible sources to determine the atmospheric distillation yields. Those sources include BP (2019), Equinor (2019), Total Oil Trading SA (2019), ExxonMobil (2019), Crude Oil Monitor (2019), Ceric (2001), the National Iranian Oil Company, Treese (2015), EcoPetrol, and the Emergencies, Sciences and Technology Division of Environment Canada. Owing to the importance of U.S. LTO, we illustrate the Eagle Ford assay in Figure A3.

Additionally, the hydrocracking unit in the model has been modified to also yield intermediate quantities of jet fuel. The yields of other products in the downstream units of atmospheric distillation are the same as the values used by KAPSARC (2016). The data are available upon request.

Because Saudi Arabia has the single largest oil refining operation in the Middle East, we use the Saudi Aramco specifications of various products in 2014 for this region. The product specifications for Africa are derived from the African Refiners Association. Those for Australasia are derived from the Mangalore Refinery and Petrochemicals Limited's Indian Standard for Petroleum Products Specifications. Those for North America and Europe come from the EIA (2018) documentation for the National Energy Modeling System. The remaining products and regions are estimated using Saudi Arabian specifications. We include ethanol blending in this version of the model, and we take its fuel properties from Thakur and Kaviti (2018).

Figure A3. Eagle Ford crude oil assay (\%wt).

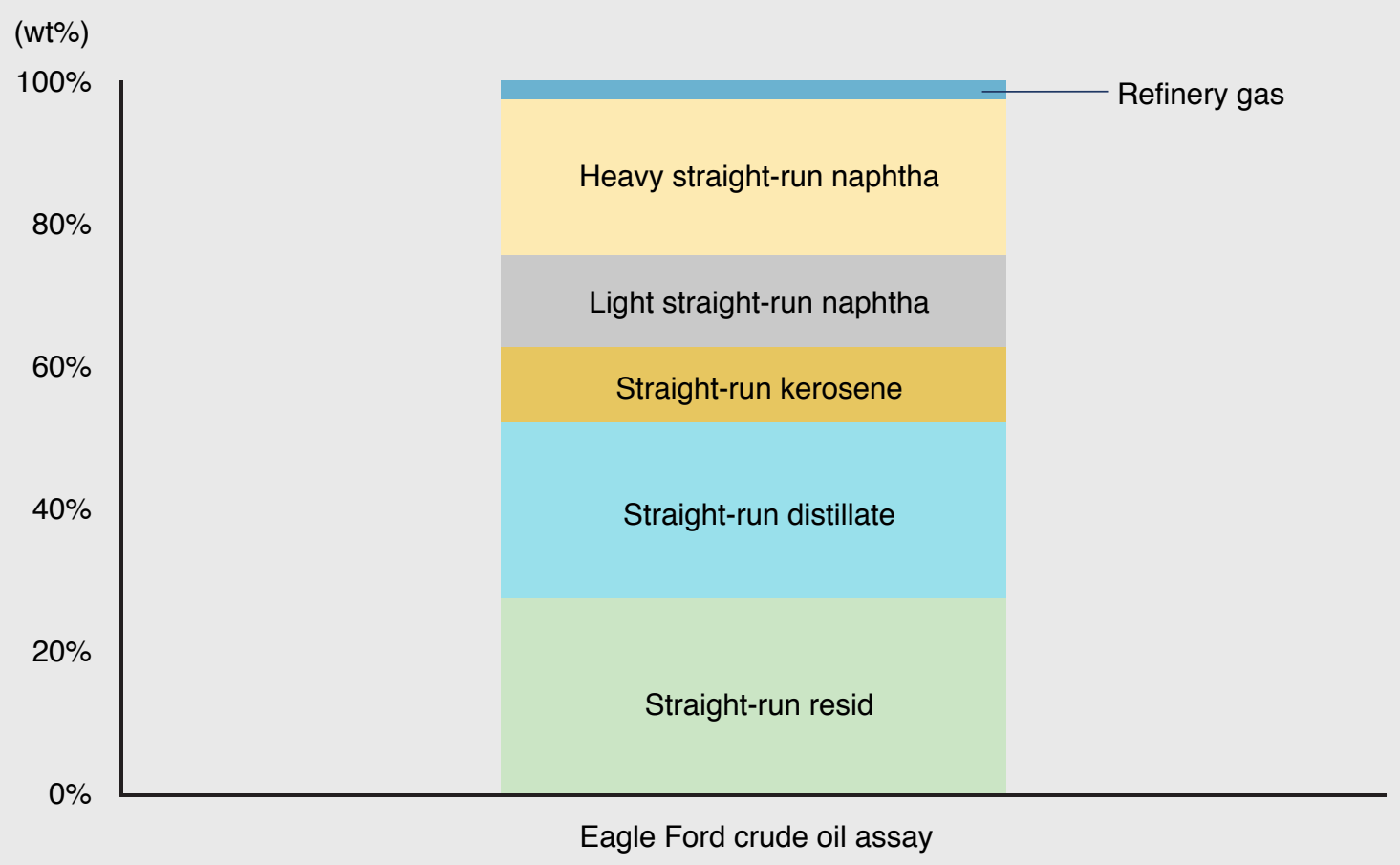

Source: Equinor 2019. 
The prices of various grades of crude oil are obtained from the Bloomberg Terminal for 2017. All grades' differentials with respect to Brent crude oil are kept fixed in real terms until 2030. Specifically, the price differential of U.S. LTO is assumed to always be $\mathbf{- \$ 6 . 6 6}$ dollars per barrel relative to Brent crude oil. Because this assumption is critical, we run a sensitivity analysis with a wide range of price differentials for the LTO grade. We surmise that if a greater LTO supply materializes, oil-exporting countries may try to either maintain oil prices by reducing production or maintain production and let oil prices fall. Historical Brent crude oil prices are obtained from the EIA, and projected prices are taken from the IEA (2019a). These prices are shown in Table A1. The prices of oxygenated methyl tert-butyl ether and ethanol are obtained from the Renewable Fuels Association (RFA 2019) and are kept constant until 2030. Finally, the prices of refined oil products are taken as the marginal costs of production, as determined by the model.

Table A1. Brent crude oil prices used in the model.

\begin{tabular}{l|c|c|c|c|c} 
Year & 2017 & 2020e & 2024e & 2027e & 2030e \\
\hline Brent price (\$/bbl) & 54.35 & 40.00 & 59.20 & 73.60 & 88.00
\end{tabular}

Sources: EIA for the 2017 price, IEA (2019a) for projected 2030 prices, authors' estimates for 2020 through 2030 based on linear interpolations.

Note: "e" stands for estimated.

Regional 2017 industrial electricity prices are estimated as weighted averages by refining capacity using data from the IEA (2019c). Some regions' electricity prices are estimated as those of the dominant country in the region. For example, the U.S. is used for the North America estimates.

The costs of transporting crude oils across regions are taken from Alkathiri et al. (2017). Their data, which are pertinent to 2012, are updated to 2017. We make the update using the change in Brent crude oil prices and the elasticity of oil cargo freight rates with respect to the oil price from the UN Conference on Trade and Development (2010). We then project freight costs using this oil price elasticity and the expected Brent prices. The same costs are used as a proxy for refined oil products' costs. However, we realize that their costs should differ, as smaller vessels are used for these products. 


\section{Model validation}

We take several steps to validate the model's output for 2017. We compare several parameters to actual 2017 data and use personal judgement to assess the product prices.

- Crude oil intake in oil refineries is within $0.01 \%$ of the actual value (IEA 2019b).

- The trade quantities of crude oil and refined oil products among the eight regions are within $4.33 \%$ and $3.45 \%$, respectively, of the actual values (BP 2018).

- Oil refineries build less than $4 \%$ of the existing atmospheric distillation capacity in the long run.

- In 2017, the marginal values of the products' demand constraints are in line with global market prices.

It is also worth mentioning that we find no evidence of significant changes to the results if we consider seasonal operations. Thus, we choose to use annual time steps to ensure a manageable model size. 


\section{Notes}

(1) 


\section{About the Author}

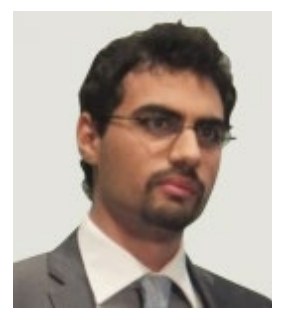

\section{Walid Matar}

Walid is a research fellow at KAPSARC working on energy systems models, such as the KAPSARC Energy Model, and satellite projects, such as the residential electricity use model. Walid holds a Master of Science degree in mechanical engineering from North Carolina State University and a Bachelor of Science degree in the same field from the University of South Carolina.

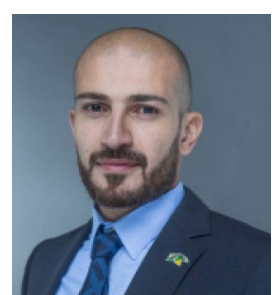

\section{Rami Shabaneh}

Rami Shabaneh is a senior research associate with a focus on global gas and liquids markets. Rami has over 13 years of research and industry experience analyzing energy markets and energy policy. Before joining KAPSARC, Rami worked at Cenovus Energy as a market fundamentals analyst, providing analytic support on specific issues affecting North American gas, natural gas liquids and condensate markets. His work informed the company's hedging strategies. Before working at Cenovus Energy, Rami spent three years as an integral member of the fuels and power research team at the Canadian Energy Research Institute. He holds an M.Sc. in sustainable energy development from the University of Calgary.

\section{About the Project}

This study is part of the project, Future of North American Tight Oil. It deals with the prevailing question raised by analysts regarding whether the light quality of American shale oil will cause an issue for oil refineries in the future. 
INAPSARC

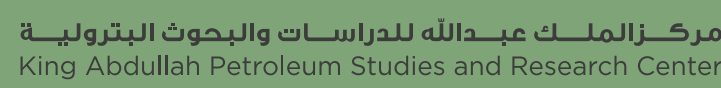

www.kapsarc.org 